\title{
Why should cannabis be considered doping in sports?
}

\author{
Mateus M. Bergamaschi ${ }^{1,2}$ and José Alexandre S. Crippa ${ }^{1,2 *}$ \\ 1 Department of Neuroscience and Behavior, Ribeirão Preto Medical School, University of São Paulo, Ribeirão Preto, São Paulo, Brazil \\ 2 National Institute for Translational Medicine, CNPq, Porto Alegre, Brazil \\ ${ }^{*}$ Correspondence: jcrippa@fmrp.usp.br \\ Edited by: \\ Elizabeth C. Temple, University of Ballarat, Australia \\ Reviewed by: \\ Elizabeth C. Temple, University of Ballarat, Australia
}

Recent debate and cases involving elite athletes raised the question whether or not Cannabis sativa (cannabis) should be considered doping in sports. Results from a 2010 report in the United States (Substance Abuse and Mental Health Services Administration, 2011) showed that cannabis is the most used illicit drug, with 17.4 million users smoking cannabis and 6.9 million users smoking cannabis on a daily or near daily basis. The World AntiDoping Agency (WADA) included cannabis in its Prohibited List in 2004, claiming that cannabis may improve performance in some sports and is an illegal drug in most countries (Huestis et al., 2011); however, the inclusion of a substance in the Code (World Anti-Doping Agency, 2009) is complex, requiring intense debate among delegates and the fulfillment of specific criteria. For instance, Section 4 of the Code establishes that a substance be considered for inclusion in the Prohibited List if it is a masking agent or meets two of the three following criteria: (i) potential to enhance performance in sports - smoked cannabis affects cognition and performance, causes memory loss, executive function, and motor impairment, among other undesirable effect (Saugy et al., 2006). Cannabis smoking can be helpful for some activities such as extreme sports, as it improves muscle relaxation, reduces anxiety, and extincts fear memories (e.g., negative experiences) leading to enhanced performance. It is also worthwhile to note that cannabis smoking improves sleep time and recovery, which may favor performance when an athlete is facing multiple competitions in a short period of time. In light of these positive effects, one can assume cannabis is a doping substance that relaxes the mind and improves recovery (Huestis et al., 2011); (ii) potential or actual health risk - cannabis' cognitive effects in chronic users are still unclear, but it may downregulate CB1 receptors, affect executive functions, and cause motor impairment, reversed only after weeks of abstinence (Hirvonen et al., 2012). It seems unlikely that athletes are chronic cannabis smokers due to the detrimental effects of chronic use including inconsistent performance, concentration, and motivation. Cyclists who smoked cannabis had a 1-min decrease in maximal exercise performance at $10 \mathrm{~min}$ after smoking (Renaud and Cormier, 1986). These negative effects on cognition and performance can impair critical skills (e.g., decision making, vigilance, alertness) required in high-risk sports to avoid accidents and/ or injuries; or (iii) violation of the spirit of sport - doping is essentially contrary to the spirit of sport, which is the principle of Olympism, characterized by several values, such as ethics, fair play and honesty, health, respect for rules and laws, and respect for self and other participants (World AntiDoping Agency, 2009).

Over 60 cannabinoids are present in cannabis, with $\Delta 9$-tetrahydrocannabinol (THC) the main psychoactive constituent and responsible for the observed toxic effects after smoking, while other cannabinoids are responsible for minor effects, such as cannabinol (CBN), which is $10 \%$ as psychoactive as THC (Huestis, 2005). THC is lipophilic and stores in several organs, especially in adipose tissue; this extensive body burden explains the prolonged cannabinoid detection rate in blood and urine for at least 4 weeks in chronic daily cannabis smokers (Lowe et al., 2009; Bergamaschi et al., 2013). The WADA (World Anti-Doping Agency, 2013) establishes a $15 \mathrm{ng} / \mathrm{mL}$ urinary 11-nor-9-carboxy-THC (THCCOOH) threshold; urine analyses involves $\mathrm{THCCOOH}$-glucuronide conjugates cleavage, which significantly increases free $\mathrm{THCCOOH}$ concentrations and detection time. Urinary THCCOOH concentrations above the $15 \mathrm{ng} / \mathrm{mL}$ threshold are considered Adverse Analytical Findings and may be interpreted as a violation of anti-doping rules (World AntiDoping Agency, 2009). Studies showed that even occasional and single cannabis smoking might yield a THCCOOH positive result ( $\geq 15 \mathrm{ng} / \mathrm{mL})$ for up to 5 days (Huestis et al., 1996). Thus, consuming cannabis even weeks before a match may imply a considerable risk of being detected in a doping test. In light of this considerable risk, some users started using a new preparation of herbal smoking blends named "Spice." Such substances are highly potent cannabinoid analogs, with unknown and potentially harmful toxicological properties that may cause prolonged intoxication. These substances mimic or worsen cannabis' toxic effects provoking cognitive and motor impairment (UNODC, 2011).

The non-psychoactive cannabidiol (CBD) is anxiolytic in humans following a single dose (Zuardi et al., 1993; Bergamaschi et al., 2011); decreased anxiety and fear memories extinction after oral CBD intake may enhance sports performance with no "violation" of the Code, as no THCCOOH is detected in urine. One way to protect athletes' health and to promote health, fairness, and equality in sports is to include any illicit drugs, their constituents and analogs in the anti-doping program. The sports may assist to create educational program for youth and athletes as an alternative to keep them away from drugs and to preserve the intrinsic value about the "spirit of sport."

\section{REFERENCES}

Bergamaschi, M. M., Karschner, E. L., Goodwin, R. S., Scheidweiler, K. B., Hirvonen, J., Queiroz, R. H. C., et al. (2013). Impact of prolonged cannabinoid excretion in chronic daily cannabis smokers' blood on per se drugged driving laws. Clin. Chem. 59, 519-526. 
Bergamaschi, M. M., Queiroz, R. H., Chagas, M. H., De Oliveira, D. C., De Martinis, B. S., Kapczinski, F., et al. (2011). Cannabidiol reduces the anxiety induced by simulated public speaking in treatment-naive social phobia patients. Neuropsychopharmacology 36, 1219-1226.

Hirvonen, J., Goodwin, R. S., Li, C. T., Terry, G. E., Zoghbi, S. S., Morse, C., et al. (2012). Reversible and regionally selective downregulation of brain cannabinoid $\mathrm{CB}(1)$ receptors in chronic daily cannabis smokers. Mol. Psychiatry 17, 642-649.

Huestis, M. A. (2005). Pharmacokinetics and metabolism of the plant cannabinoids, delta9-tetrahydrocannabinol, cannabidiol and cannabinol. Handb. Exp. Pharmacol. 168, 657-690.

Huestis, M. A., Mazzoni, I., and Rabin, O. (2011). Cannabis in sport: anti-doping perspective. Sports Med. 41, 949-966.

Huestis, M. A., Mitchell, J. M., and Cone, E. J. (1996). Urinary excretion profiles of 11-nor-9-carboxy9-tetrahydrocannabinol in humans after single smoked doses of marijuana. J. Anal. Toxicol. 20, 441-452.
Lowe, R., Abraham, T., Darwin, W., Herning, R., Cadet, J., and Huestis, M. (2009). Extended urinary Delta9tetrahydrocannabinol excretion in chronic cannabis users precludes use as a biomarker of new drug exposure. Drug Alcohol Depend. 105, 24-32.

Renaud, A. M., and Cormier, Y. (1986). Acute effects of marihuana smoking on maximal exercise performance. Med. Sci. Sports Exerc. 18, 685-689.

Saugy, M., Avois, L., Saudan, C., Robinson, N., Giroud, C., Mangin, P., et al. (2006). Cannabis and sport. Br. J. Sports Med. 40(Suppl. 1), i13-i15.

Substance Abuse and Mental Health Services Administration. (2011). Results from the 2010 National Survey on Drug Use and Health: Summary of National Findings, NSDUH Series H-41, HHS Publication No. (SMA) 11-4658. Rockville, MD: Substance Abuse and Mental Health Services Administration.

UNODC. (2011). World Drug Report 2011. Vienna: United Nations Publication, Sales No. E.11.XI.10.

World Anti-Doping Agency. (2009). World Anti-Doping Code. Montreal, QC: World Anti-Doping Agency.

World Anti-Doping Agency. (2013). WADA Technical Document: Decision Limits for the Confirmatory
Quantification. The World Anti-Doping Code. International Standards for Laboratories, TD2013DL. Montreal: World Anti-Doping Agency.

Zuardi,A.W., Cosme, R.A., Graeff, F. G., and Guimaraes, F. S. (1993). Effects of ipsapirone and cannabidiol on human experimental anxiety. J. Psychopharmacol. 7, 82-88.

Received: 20 February 2013; accepted: 28 April 2013; published online: 15 May 2013.

Citation: Bergamaschi MM and Crippa JAS (2013) Why should cannabis be considered doping in sports? Front. Psychiatry 4:32. doi: 10.3389/fpsyt.2013.00032

This article was submitted to Frontiers in Addictive Disorders and Behavioral Dyscontrol, a specialty of Frontiers in Psychiatry.

Copyright (c) 2013 Bergamaschi and Crippa. This is an open-access article distributed under the terms of the Creative Commons Attribution License, which permits use, distribution and reproduction in other forums, provided the original authors and source are credited and subject to any copyright notices concerning any third-party graphics etc. 